\title{
Preparation Technics and Properties Research of Peppermint Essential Oil Microcapsules
}

\author{
Xiaojuan Zhang, Bo Liang*, Ye Dü, Guanzheng Wang, Yingying Sun, Rui Yao, Ximao Cao \\ and Zhonghuan Zhang
}

Institute of Marine intelligent equipment, Harbin University of Science and Technology, Harbin, China.

Corresponding author email: Bo Liang, bliang0325@163.com

ayedurongcheng@163.com

Keywords: microcapsules; peppermint essential oil; embedding rate; oxidation stability.

Abstract: Peppermint essential oil is widely used in food industry, but it is easy to be oxidized. In order to improve its oxidation stability, the peppermint essential oil microcapsule was prepared by single factor experiment and response surface optimization experiment in the paper. The effect of core wall ratio, $\mathrm{pH}$ value of complex coagulation and agitation speed on the embedding rate of peppermint essential oil microcapsules was studied respectively. The optimum experimental conditions were obtained as follows: core wall ratio, 1.9:1; $\mathrm{pH}$ value of complex condensation, 4.0; and the optimal agitation speed, 400 $/ \mathrm{min}$. The maximum embedding rate of peppermint essential oil microcapsules was $89.67 \%$. POV value showed that the oxidative stability of peppermint essential oil microcapsules was significantly higher than peppermint essential oil.

\section{Introduction}

Microencapsulation technology is the use of natural or synthetic polymer compounds to form a film, the core material is embedded in a closed microcapsule to avoid or reduce the impact of external environment on the core material [1]. Peppermint essential oil is unstable and easy to oxidize, so it is often made into microcapsules [2]. The methods of preparing microcapsules are interfacial polymerization, in situ polymerization, orifice method, spray drying, molecular packing and multiple emulsion method [3]. These manufacturing methods have the disadvantages of complex operation, long time consuming, high temperature material loss, low output and difficult to control, etc. Due to its good controlled release and heat resistance characteristics of the method of complex condensation was used in this paper as a method to prepare microcapsules of peppermint essential oil, so as to improve the embedding rate and oxidation stability of peppermint essential oil microcapsules.

\section{Experiment}

\subsection{Experimental Reagent}

The information of the experimental drugs used in the experiment is shown in table 1.

TABLE 1. Experimental drugs

\begin{tabular}{c|c|c}
\hline Name & Content (\%) & Manufacturer \\
\hline Chitosan & $\geq 98 \%$ & Qingdao Jifa New Materials Co., Ltd. \\
\hline Arabia Gum & $\geq 99 \%$ & Wuhan Geeyeschem Chemical Co., Ltd. \\
\hline Peppermint Essential Oil & $\geq 99 \%$ & Jishui Shengyuan Fragrance Factory \\
\hline Transglutaminase & $\geq 99 \%$ & Xi'an LAVIA Biotechnology Co., Ltd. \\
\hline Acetic Acid & $\geq 90 \%$ & Xi'an LAVIA Biotechnology Co., Ltd. \\
\hline Sodium Hydroxide & $\geq 99 \%$ & Henan Yusheng Chemical Co., Ltd. \\
\hline
\end{tabular}

\subsection{Experimental Instruments and Equipment}

The experimental instruments and equipment used in the experiment are shown in table 2. 
TABLE 2. Experimental instruments and equipment

\begin{tabular}{c|c|c}
\hline Name of Instrument & Model & Manufacturer \\
\hline $\begin{array}{c}\text { Electronic Balance } \\
\begin{array}{c}\text { Temperature Control Magnetic } \\
\text { Stirrer }\end{array}\end{array}$ & BSA124S & Shanghai Youyi Instrument Co., Ltd. \\
\hline Ultrasonic Cleaner & KQ-250E & $\begin{array}{c}\text { Jiangsu Jinyi Instrument Technology Co., } \\
\text { Ltd. }\end{array}$ \\
\hline Biomicroscope & PH50-3A43L-PL & $\begin{array}{c}\text { Jiangxi Phoenix Optical Technology Co., } \\
\text { Ltd }\end{array}$ \\
\hline PH Meter & SG78 & Mettler Toledo Instruments Co., Ltd. \\
\hline Freezer & FCD-178XHT & $\begin{array}{c}\text { Qingdao Haier Special Electric Freezer Co., } \\
\text { Ltd. }\end{array}$ \\
\hline
\end{tabular}

\subsection{Preparation of Microcapsules}

Refer to the method of Xia Huiting et al[4]. Prepare Arabia gum solution and chitosan solution in advance, and reserve it for use. Take a certain amount of arabic gum solution and add a certain proportion of peppermint essential oil to mix evenly, emulsify at 10000r / min for 3min at high speed and chitosan solution is also emulsified at the same speed for the same time. Drop by drop, the chitosan solution is added, stir with a temperature controlled magnetic stirrer at $400 \mathrm{r} / \mathrm{min}$ for $10 \mathrm{~min}$, acetic acid with a mass fraction of $10 \%$ was added to adjust the $\mathrm{pH}$ to the appropriate value, complex coacervation $30 \mathrm{~min}$. The water bath cooled the system to $10^{\circ} \mathrm{C}$ for $15 \mathrm{~min}$. Transglutaminase was added and cured at $10^{\circ} \mathrm{C}$ for $1 \mathrm{~h}$. Add $10 \% \mathrm{NaOH}$ solution to adjust $\mathrm{pH}$ value to 6 and continue curing at room temperature for $12 \mathrm{~h}$. Wash and filter with distilled water for 3 times to obtain wet microcapsules.

\subsection{Single Factor Experiment}

\subsubsection{Selection of Agitation Speed}

Other technological conditions and external parameters were fixed, and the agitation speeds of the complex condensation were changed to be $300 \mathrm{r} / \mathrm{min}, 350 \mathrm{r} / \mathrm{min}, 400 \mathrm{r} / \mathrm{min}, 450 \mathrm{r} / \mathrm{min}$, and $500 \mathrm{r} / \mathrm{min}$, respectively, the morphology of condensate was observed by biomicroscope and the optimum agitation speed was determined by screening.

\subsubsection{Selection of Complex Coagulation PH Value}

On the basis of selecting the optimal agitation speed, other process conditions and external parameters were fixed, and the $\mathrm{pH}$ values of complex condensation were changed to 3.0, 3.5, 4.0, 4.5 and 5.0, respectively, the morphology of condensate was observed by biomicroscope and the optimal $\mathrm{pH}$ value of complex condensate was determined by screening.

\subsubsection{Selection of Core Wall Ratio}

On the basis of selecting the optimal agitation speed and the optimal $\mathrm{pH}$ value of complex condensation, other technological conditions and external parameters were fixed and the core wall ratio of complex condensation was changed to be $1: 1,1: 2,1: 3,2: 1$ and $3: 1$, the morphology of condensate was observed by biomicroscope and the optimum core wall ratio was determined by screening.

\subsubsection{Calculation of Embedding Rate}

Refer to the method of Chen Lin et al[5].

$$
\text { Embedding rate }=\left(1-\frac{\text { Surface oil content of microcapsules }}{\text { Total oil content of microcapsules }}\right) \times 100 \%
$$




\subsection{Response Surface Experiment}

In order to obtain the best preparation technology, on the basis of single factor experiment, the response surface experiment was used to optimize the experimental design, with agitation speed, complex condensation $\mathrm{pH}$ value and core wall ratio as the influencing factors, and embedding rate as the determination index. The level of experimental factors on the response surface is shown in table 3 .

TABLE 3. Horizontal table of factors affecting response surface

\begin{tabular}{c|c|c|c}
\hline \multirow{2}{*}{ Level } & \multicolumn{3}{|c}{ Factor } \\
\cline { 2 - 4 } & A & B & C \\
& Agitation Speed (r/min) & PH Value of Complex Condensation & Core Wall Ratio \\
\hline 1 & 350 & 3.5 & $1: 1$ \\
\hline 0 & 400 & 4.0 & $2: 1$ \\
\hline-1 & 450 & 4.5 & $3: 1$ \\
\hline
\end{tabular}

\section{Results and Discussion}

\subsection{Single-factor Experiment}

\subsubsection{Agitation Speed}

The influence of agitation speed on the morphology of microcapsules prepared by complex condensation method is shown in Fig.1. The effect of agitation speed on the embedding rate of microcapsules is shown in Fig.2.

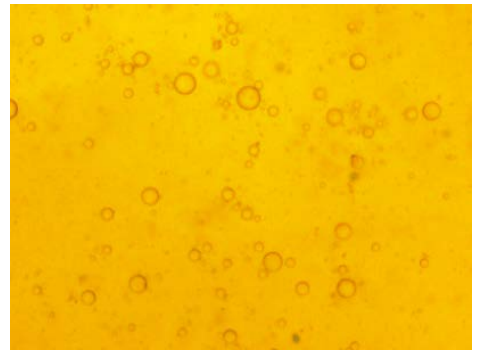

(a)300r/min

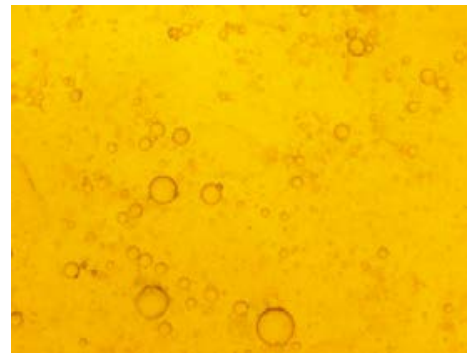

(b)350r/min

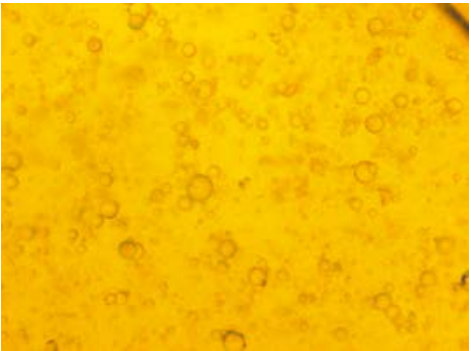

(c) $400 \mathrm{r} / \mathrm{min}$

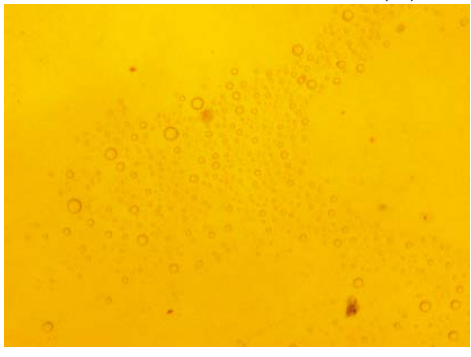

(d) $450 \mathrm{r} / \mathrm{min}$

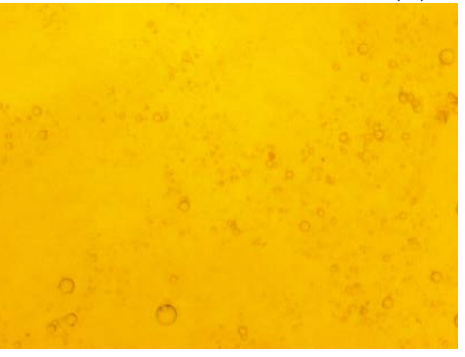

(e) $500 \mathrm{r} / \mathrm{min}$

Figure 1. Effect of agitation speed on microcapsule morphology (60 times) 


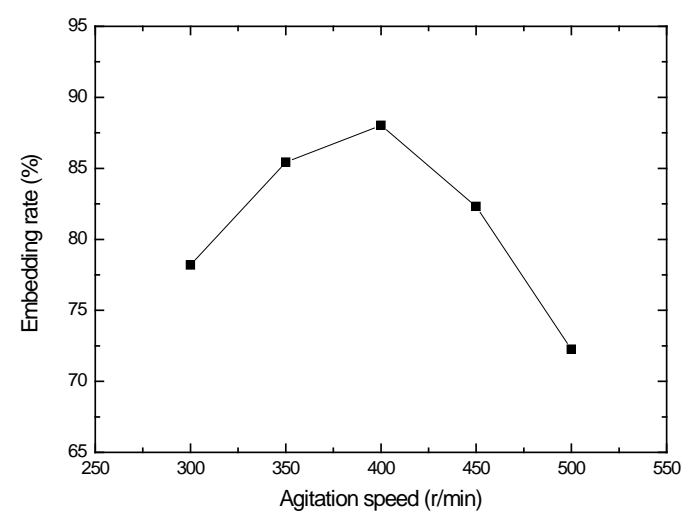

Figure 2. Effect of agitation speed on microencapsulation rate

As can be seen from figure 1, the number of microcapsules first increased and then decreased with the increase of agitation speed. When the agitation speed was $400 \mathrm{r} / \mathrm{min}$, the microcapsules observed under the microscope had good shape and uniform dispersion, and the embedding effect was the best, with the increase of agitation speed, the microcapsules formed gradually decrease in size, smaller in oil content and easier to aggregate. The best agitation speed is 400r / min based on the shape, particle size and embedding rate.

It can be seen from Figure 2 that with the increase of agitation speed, the embedding rate of microcapsules increases first and then decreases. When the agitation speed is $400 \mathrm{r} / \mathrm{min}$, the maximum embedding rate is taken.

\subsubsection{The PH of the Complex Condensation}

The influence of complex condensation $\mathrm{pH}$ value on the morphology of microcapsules prepared by complex condensation is shown in Fig.3. The effect of complex condensation $\mathrm{pH}$ value on the embedding rate of microcapsules is shown in Fig.4.

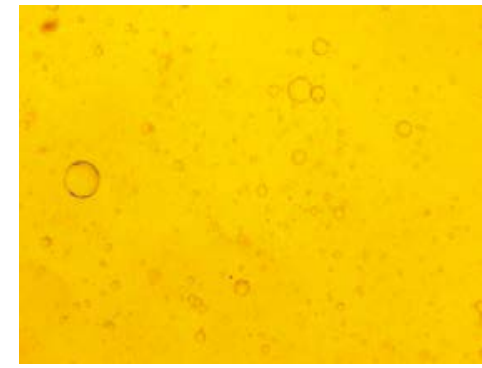

(a) $\mathrm{pH}=3.0$

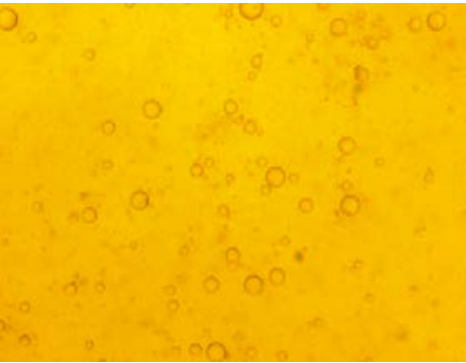

(b) $\mathrm{pH}=3.5$

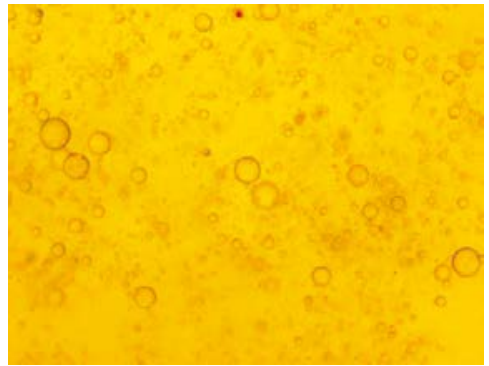

(c) $\mathrm{pH}=4.0$

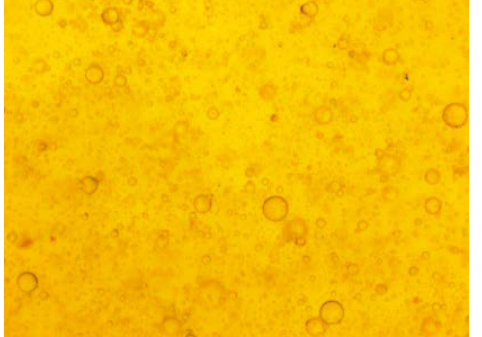

(d) $\mathrm{pH}=4.5$

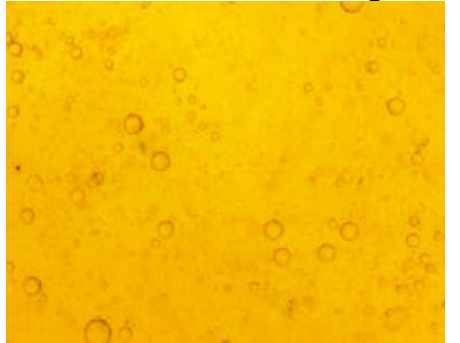

(e) $\mathrm{pH}=5.0$

Figure 3. Influence of $\mathrm{pH}$ value of complex condensation on microcapsule morphology (60 times) 


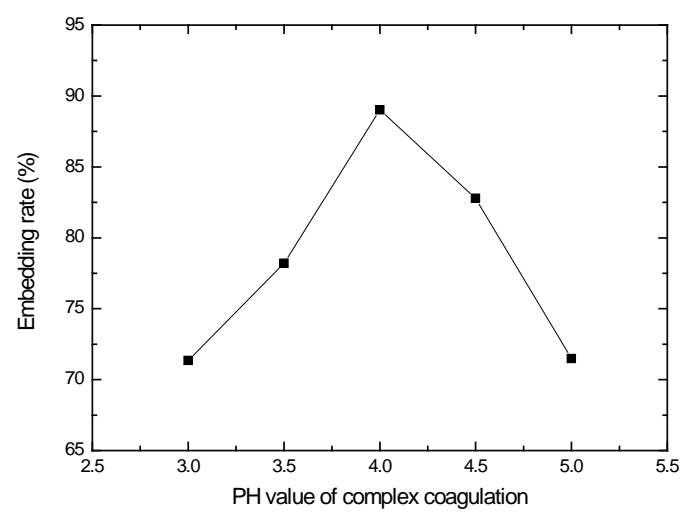

Figure 4. Effect of different $\mathrm{pH}$ value of complex coagulation on the embedding rate of microcapsules

It can be seen from figure 3 that either too high or too low $\mathrm{pH}$ value will reduce the embedding rate of microcapsules, while when the $\mathrm{pH}$ value is too low, the solubility of chitosan is large and the reaction of the two wall materials is insufficient, and the embedding rate is low. When the $\mathrm{pH}$ is too high, it is close to the isoelectric point, which limits the reaction between chitosan and Arabic gum, so the embedding rate is reduced.

It can be seen from Figure 4 that the embedding rate of the microcapsules increases first and then decreases with the increase of the complex condensation $\mathrm{pH}$ value. When the $\mathrm{pH}$ value of complex condensation was 4.0 , the maximum embedding rate is taken.

\subsubsection{Core Wall Ratio}

The influence of core wall ratio on the morphology of microcapsules prepared by complex condensation is shown in Fig.5. The effect of core wall ratio on microcapsule embedding rate is shown in Fig.6.

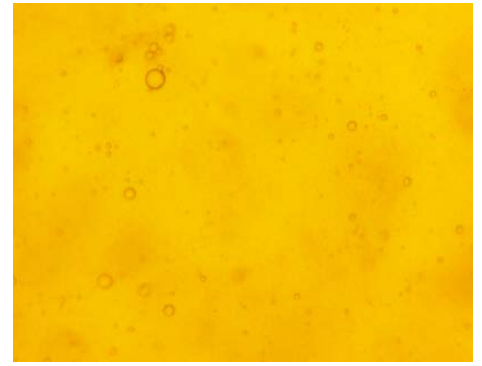

(a)1:3

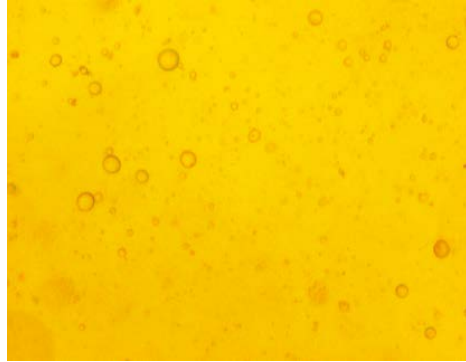

(b)1:2

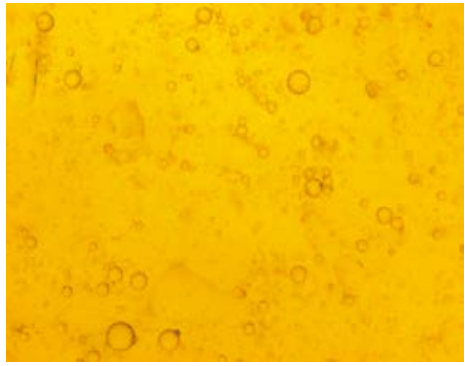

(c)1:1

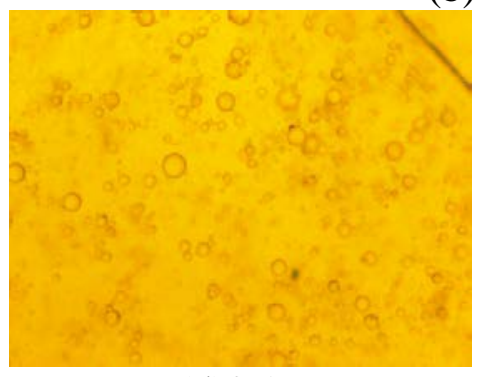

(d)2:1

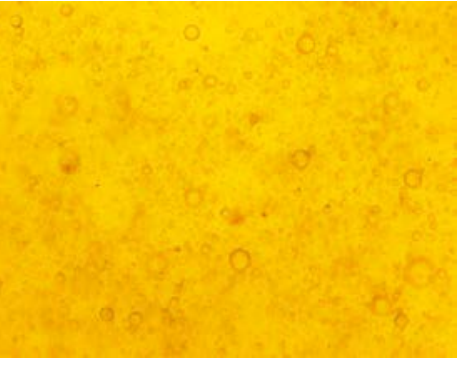

(e)3:1

Figure 5. Influence of core wall ratio on microcapsule morphology (60 times) 


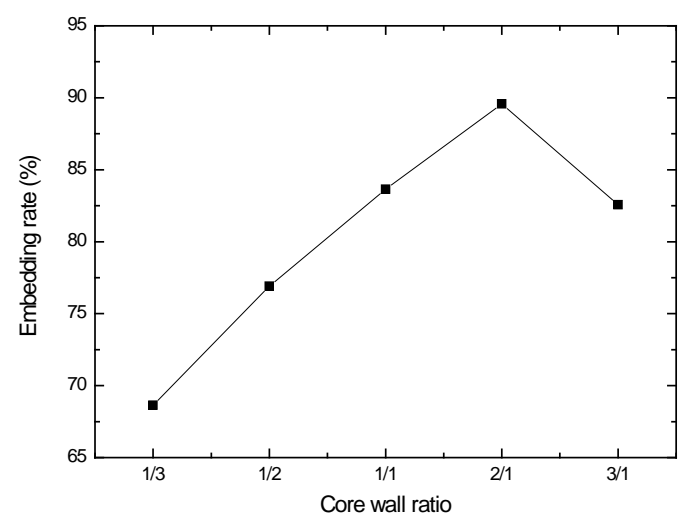

Figure 6. Effect of core wall ratio on microcapsule embedding rate

As can be seen from figure 5, the shape of microcapsules was less affected by the ratio of different core walls, and the embedding of microcapsules first increased and then decreased with the decrease of wall material concentration, when the ratio of 2:1 core wall under a microscope to the good and the amount of microcapsule morphology, with the increase of concentration of core material oil content increased, the core material of wall surface complex condensate decreases, the observed microcapsules form fuzzy and there are many unformed microcapsules, microcapsules in reducing the number of the microcapsule embedding rate gradually decreased.

It can be seen from Figure 6 that the embedding rate of microcapsules increases first and then decreases with the increase of core wall ratio, when the core wall ratio is 2:1, the maximum embedding rate is taken.

\subsection{Response Surface Experiment}

\subsubsection{Analysis of Response Surface Experiment Results}

The response surface experimental design scheme and experimental results are shown in table 4 .

TABLE 4. Experimental design and results of response surface

\begin{tabular}{c|c|c|c|c}
\hline $\begin{array}{c}\text { Test } \\
\text { Number }\end{array}$ & $\begin{array}{c}\text { A-Agitation } \\
\text { Speed }\end{array}$ & $\begin{array}{c}\text { B-PH Value of Complex } \\
\text { Condensation }\end{array}$ & $\begin{array}{c}\text { C-Core Wall } \\
\text { Ratio }\end{array}$ & $\begin{array}{c}\text { Y-Embedding } \\
\text { Rate/\% }\end{array}$ \\
\hline 1 & 0 & 0 & 0 & 89.76 \\
\hline 2 & 1 & 0 & -1 & 79.54 \\
\hline 3 & 0 & 0 & 0 & 90.81 \\
\hline 4 & 0 & 1 & 1 & 74.62 \\
\hline 5 & -1 & -1 & 0 & 81.25 \\
\hline 6 & -1 & 0 & 1 & 79.39 \\
\hline 7 & 1 & 0 & 1 & 80.01 \\
\hline 8 & 1 & 1 & 0 & 79.85 \\
\hline 9 & 0 & -1 & 1 & 75.41 \\
\hline 10 & 0 & 1 & -1 & 77.84 \\
\hline 11 & 0 & 0 & 0 & 89.94 \\
\hline 12 & 0 & 0 & -1 & 89.97 \\
\hline 13 & 0 & -1 & 0 & 78.25 \\
\hline 14 & -1 & 1 & -1 & 81.62 \\
\hline 15 & -1 & 0 & 0 & 80.27 \\
\hline 16 & 0 & 0 & 0 & 90.98 \\
\hline 17 & 1 & -1 & & 79.63 \\
\hline
\end{tabular}

3.2.2 Response Surface Analysis of Variance Results 
TABLE 5. Variance analysis of response surface regression model

\begin{tabular}{c|c|c|c|c|c}
\hline Source & Sum of Squares & df & Mean Square & F Value & p-value Prob $>$ F \\
\hline Model & 496.52 & 9 & 55.17 & 55.26 & $<0.0001$ \\
\hline A- Agitation Speed & 1.53 & 1 & 1.53 & 1.53 & 0.2554 \\
\hline B- PH Value of Complex Condensation & 0.047 & 1 & 0.074 & 0.047 & 0.8353 \\
\hline C- Core Wall Ratio & 5.23 & 1 & 5.23 & 5.24 & 0.0559 \\
\hline AB & $5.625-003$ & 1 & $5.625-003$ & $5.635-003$ & 0.9423 \\
\hline AC & 0.46 & 1 & 0.46 & 0.46 & 0.5210 \\
\hline BC & 0.036 & 1 & 0.036 & 0.036 & 0.8546 \\
\hline A2 & 43.55 & 1 & 43.55 & 43.62 & 0.0003 \\
\hline B2 & 177.27 & 1 & 177.27 & 177.57 & $<0.0001$ \\
\hline C2 & 222.75 & 1 & 222.75 & 223.14 & $<0.0001$ \\
\hline Residual & 6.99 & 7 & 1.00 & & \\
\hline Lack of Fit & 5.74 & 3 & 1.91 & 6.11 & 0.0565 \\
\hline Pure Error & 1.25 & 4 & 0.31 & & \\
\hline Cor Total & 503.51 & 16 & & & \\
\hline \multicolumn{5}{|l|}{$\mathrm{R} 2=0.9861$} & $\mathrm{R} 2 \mathrm{adj}=0.9683$ \\
\end{tabular}

Design expert v8.0.6 software was used to analyze the experimental data by quadratic response surface regression analysis, and the regression equation between the embedding efficiency of peppermint essential oil microcapsules and each dependent variable was obtained:

$\mathrm{Y} / \%=+90.29-0.44 \mathrm{~A}-0.076 \mathrm{~B}-0.81 \mathrm{C}-0.038 \mathrm{AB}+0.34 \mathrm{AC}-0.095 \mathrm{BC}-3.22 \mathrm{~A} 2-6.49 \mathrm{~B} 2-7.27 \mathrm{C} 2$

It can be seen from table 5 that $\mathrm{P}<0.0001$ of the model indicates that the quadratic equation model is very significant. The complex correlation coefficient was $\mathrm{R} 2=0.9861$, and the corrected correlation coefficient was $\mathrm{R} 2 \mathrm{adj}=0.9683$, indicating the high fitting degree of the regression model, the actual value is close to the predicted value with high accuracy and credibility, and the regression equation is representative. From the variance analysis results of the regression equation, it can be concluded that the unfitting term of the equation is $\mathrm{P}=0.0565>0.05$, which is not significant, indicating that the equation has good experimental fitting and small error. Therefore, the model is suitable for the optimization of the process parameters of peppermint essential oil microcapsules.

3.2.3 Response Surface and Contour Analysis
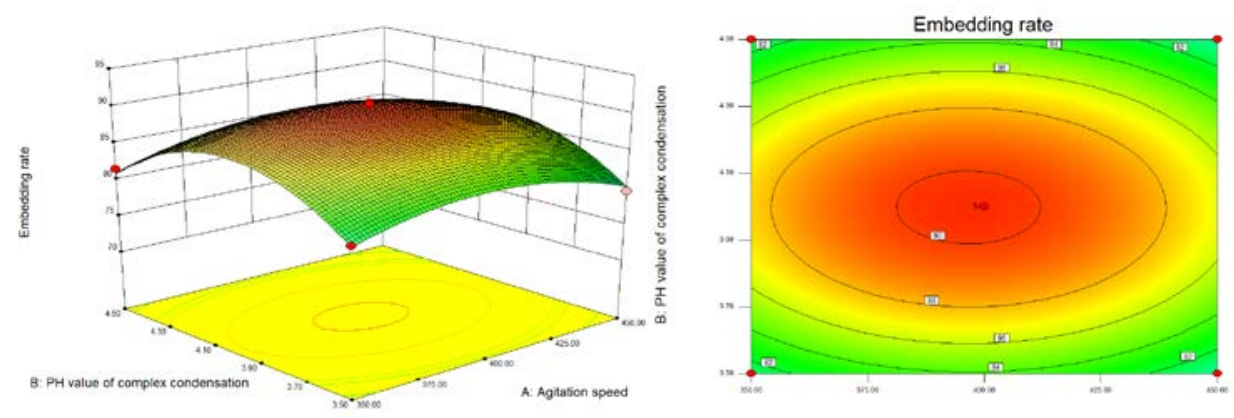

A: Agtation speed

(a) Interaction between agitation speed and $\mathrm{pH}$ value of complex coagulation 

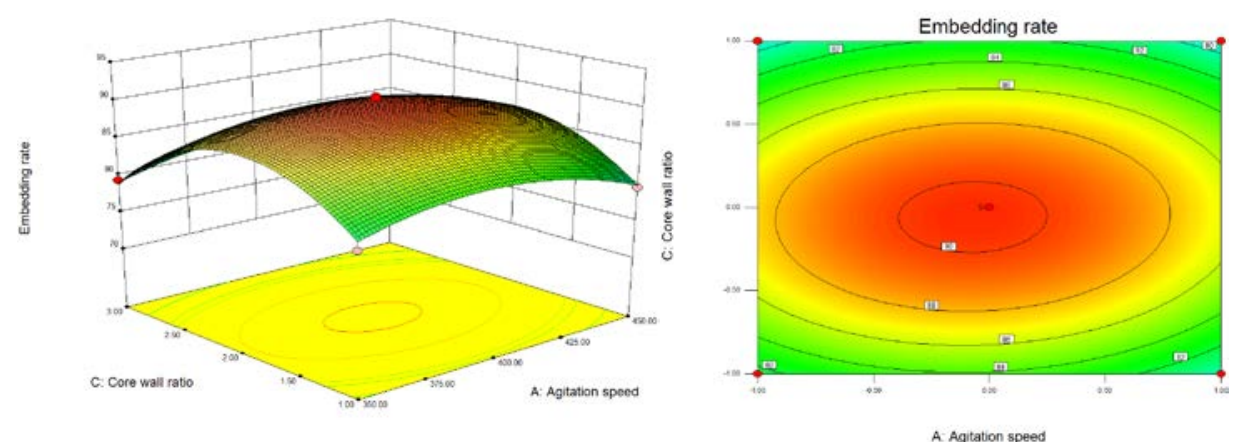

(b) Interaction between agitation speed and core wall ratio
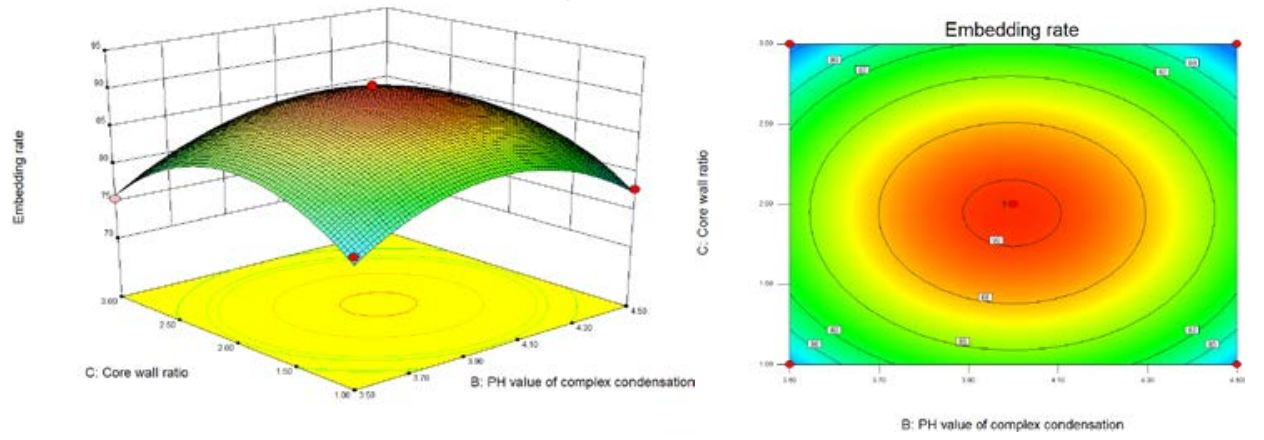

(c) Interaction between $\mathrm{pH}$ value and core wall ratio of complex coagulation Figure 7. Influence of interaction of various factors on embedding rate

It can be seen from Fig 7(a), the interaction between A (agitation speed) and $\mathrm{B}$ (pH value of complex coacervation) is not significant. It can be seen from Fig 7(b), the interaction between A (agitation speed) and $\mathrm{C}$ (core wall ratio) is significant, showing that the 3D curve is steep. It can be seen from Fig 7(c) that the interaction between $\mathrm{B}$ ( $\mathrm{pH}$ value of complex coacervation) and $\mathrm{C}$ (core wall ratio) is significant, and the contour map is the flattest, indicating that the interaction between these two factors is the largest, with the increase of core to wall ratio, embedding first increases and then decreases, when the core to wall ratio is about 2:1, the maximum value is taken. According to the results of response surface regression model, the best predicted values are: core wall ratio 1.94:1, complex coagulation $\mathrm{pH}$ value of 4.00 , agitation speed $396.45 \mathrm{r} / \mathrm{min}$, and the embedding rate is 90.33\%.

Under the condition of core to wall ratio of 1.9:1, complex coagulation $\mathrm{pH}$ value of 4.00 and agitation speed of $400 \mathrm{r} / \mathrm{min}$, the maximum embedding rate was $89.67 \%$ after repeated experiments and considering the influence of external conditions.

\subsection{Performance Analysis of Peppermint Essential Oil Microcapsules}

\subsubsection{Microstructure of Microcapsules}

Scanning electron microscope was used to observe the external structure of the microcapsule of peppermint essential oil prepared by the complex coacervation method. It can be seen from Fig.8 that the microcapsule is irregular in shape, and the surface of the microcapsule is rough and wrinkled, which may be due to the water gasification during the drying process, resulting in the excessive expansion of the microcapsule, and the shrinkage during the cooling process, resulting in the formation of wrinkles on the surface. In the figure, the microcapsule did not break, indicating that the composite wall material of chitosan and Arabic gum realized the embedding of peppermint essential oil, the composite wall material played a protective role in peppermint essential oil, and improved the stability of peppermint essential oil. 

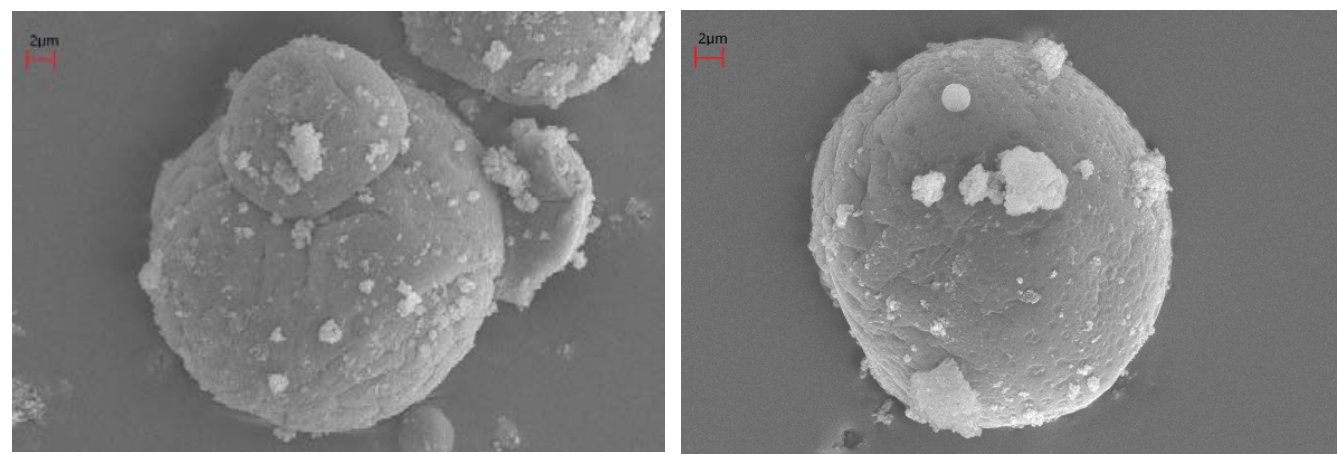

Figure 8. Electron scanning microscope of peppermint essential oil microcapsule

\subsubsection{Particle Size Distribution of Microcapsules}

The particle size of microcapsule is measured by laser particle size analyzer, and the particle size distribution of microcapsule is shown in Fig.9.

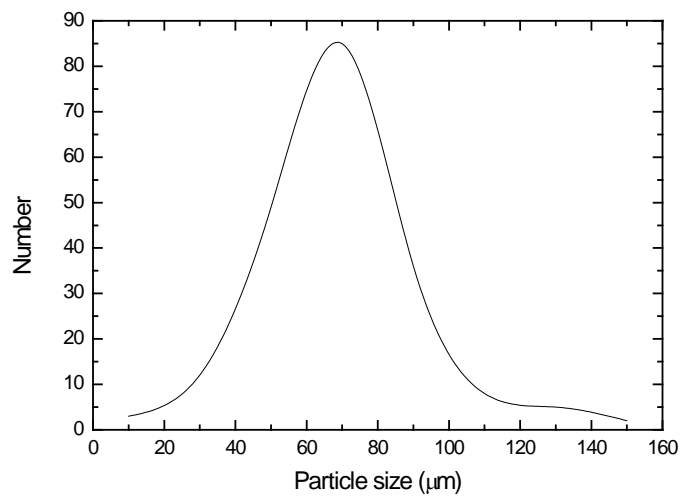

Figure 9. Particle size distribution of peppermint essential oil microcapsules

As shown in Figure 9, in the statistical samples, the particle size range of microcapsules is $0-150 \mu$ $\mathrm{m}$, and the average particle size is $69.3 \mu \mathrm{m}$. the normal distribution of the particle size of microcapsules is relatively concentrated, indicating that the particle size is uniform.

\subsubsection{Oxidative Stability of Peppermint Essential Oil Microcapsules}

Refer to the method of Zhou Xue et al[6], POV value is measured by titration. Fig.10 is a comparison of POV value growth of peppermint essential oil and peppermint essential oil microcapsules under the same external conditions in accelerated storage experiment.

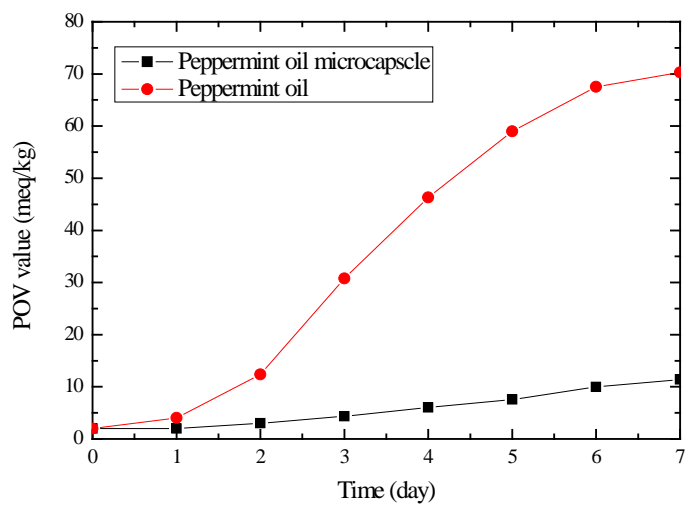

Figure 10. POV value trend of peppermint essential oil and peppermint essential oil microcapsule accelerated storage experiment 
It can be seen from Figure 10 that the POV value of peppermint essential oil microcapsule is significantly different from that of peppermint oil under accelerated storage conditions. The POV value of peppermint essential oil increased rapidly from the second day, and reached $70.29 \mathrm{meq} / \mathrm{kg}$ after 7 days storage. POV increased with the increase of hydroperoxides produced by oil oxidation, after microencapsulation, the POV value of peppermint essential oil increased slowly with time, which was much lower than that of peppermint essential oil. The results showed that the microcapsule composite wall material had a good embedding effect on the core material peppermint essential oil and hindered the influence of external conditions on peppermint essential oil, which indicated that peppermint essential oil microcapsule had a good antioxidant effect.

\section{Conclusion}

Peppermint essential oil microcapsules were prepared with chitosan and gum arabic as wall materials by complex condensation method. On the basis of single factor test, response surface method was used to optimize the preparation process, the optimal process parameters were core wall ratio of $1.94: 1$, complex coacervation $\mathrm{pH}$ value 4.00 , agitation speed of $396.45 \mathrm{r} / \mathrm{min}$, and the embedding rate was $90.33 \%$. Under the condition of $1.9: 1$ core to wall ratio, 4.00 complex coagulation $\mathrm{pH}$ value and $400 \mathrm{r} / \mathrm{min}$ agitation speed, the maximum embedding rate was $89.67 \%$ after repeated experiments and considering the influence of external conditions. Through the study of oxidation stability, it is concluded that the microencapsulation of peppermint essential oil can effectively delay the oxidation of peppermint essential oil and make it have good oxidation stability.

\section{Acknowledgements}

Thanks to the following funds for supporting this project. National Students' Platform for Innovation and Entrepreneurship Training Program (201910214080), University Nursing Program for Young Scholars with Creative Talents in Heilongjiang Province (UNPYSCT-2018205), Fundamental Research Fundation for Universities of Heilongjiang Province (LGYC2018JC052).

\section{References}

[1] Jang, I. B.; Sung, J. H.; Choi, H. J., Synthesis of microcapsule containing oil phase via in-situ polymerization [J] Journal of Materials Science. 2005, 40 (4).

[2] Hongying Li; Hongbo Wang; Jiajia Fu; Wencong Wang, Optimization of the preparation process of peppermint oil microcapsule by gelatin alginate [J] Polymer materials science and engineering. 2019, 35 (09), 142-149.

[3] Zhihua Zhang; Shurui Zhong; Fei Peng; Yingjie Zeng; Minhua Zong; Wenyong Lou, Research progress of wall material and preparation technology of microcapsules [J] Food science. 1-11.

[4] Huiting Xia; Jiaxin Yv; Ran Tian; Bin Li; Bo Tian, Preparation of olive oil microcapsules by complex coacervation [J] Chinese Journal of food. 2017, 17 (05), 108-114.

[5] Lin Chen; Rong Li; Lujie Zhang; Zitao Jiang, Study on Preparation and properties of perilla oil microcapsules by complex coacervation [J] Food industry technology. 2015, 36 (03), 232-238.

[6] Xue Zhou; Lin Lv, Evaluation of uncertainty in the determination of peroxide value in corn oil by titration [J] Modern food. 2019, (15), 163-165. 